\title{
Fontes protéicas e de amido com diferentes degradabilidades ruminais para alimentar vacas leiteiras
}

\author{
Hugo Imaizumi( ${ }^{(1)}$, Flávio Augusto Portela Santos ${ }^{(1)}$, Alexandre Vaz Pires ${ }^{(1)}$ e Sérgio de Oliveira Juchem ${ }^{(1)}$ \\ (1)Escola Superior de Agricultura Luiz de Queiroz, Dep. de Zootecnia, Caixa Postal 9, CEP 13418-900 Piracicaba, SP. \\ E-mail: hugo.imaizumi@terra.com.br, fapsanto@esalq.usp.br, alvpires@esalq.usp.br, sdjuchem@ucdavis.edu
}

\begin{abstract}
Resumo - O objetivo deste trabalho foi avaliar fontes de amido (milho moído fino x milho processado como pipoca) e fontes protéicas (farelo de soja $\mathrm{x}$ uréia $\mathrm{x}$ farinha de peixe) com degradabilidades ruminais diferentes para alimentar vacas leiteiras. Foram utilizadas 56 vacas Holandesas com 112 dias em lactação. Os tratamentos foram: MFS (milho moído fino + farelo de soja); PFS (pipoca + farelo de soja); PFP (pipoca + farelo de soja + farinha de peixe); PU (pipoca + farelo de soja + uréia). O tratamento PFS não afetou a produção de leite, mas diminuiu o teor de gordura, a produção de gordura e o teor de proteína do leite. A produção de leite foi maior no tratamento PFS do que nos tratamentos PFP e PU. O tratamento PFP diminuiu o teor de gordura, a produção de gordura e de leite corrigida para 3,5\% de gordura, mas aumentou o teor de proteína no leite.
\end{abstract}

Termos para indexação: nutrição de ruminantes, processamento de grãos, produção de leite, uréia.

\section{Protein and starch sources varying in rumen degradability to feed dairy cows}

\begin{abstract}
The objective of this work was to evaluate starch sources (fine ground x popped corn) and protein sources (soybean meal $x$ fish meal $\mathrm{x}$ urea) varying in rumen degradability in order to feed dairy cows. Fifty-six Holstein cows averaging 112 days in milk were used. The treatments were: MFS (fine ground corn + soybean meal); PFS (popped corn + soybean meal); PFP (popped corn + soybean meal + fishmeal) and PU (popped corn + soybean meal + urea). The treatment PFS did not affect milk yield, but it decreased milk fat content, milk fat yield and milk protein content, compared to MFS. Milk yield was higher for PFS than for PFP or PU. Treatment with fishmeal (PFP) decreased milk fat content, milk fat yield and 3.5\% FCM yield, but increased milk protein content.
\end{abstract}

Index terms: ruminant nutrition, grain processing, milk production, urea.

\section{Introdução}

Os carboidratos e as proteínas são os dois principais componentes nutritivos em rações para vacas leiteiras. Quantidade considerável de pesquisa tem sido publicada nos últimos 20 anos, sobre os efeitos da manipulação desses componentes em termos de metabolismo e desempenho animal.

Na década de 80 , até meados da de 90 , a técnica de suplementação com amido e proteína, resistentes à degradação ruminal, para serem digeridos no intestino delgado de vacas leiteiras, foi amplamente difundida como prática vantajosa, em razão do aumento na disponibilidade de glicose e aminoácidos essenciais para o animal. Entretanto, este conceito originou-se em hipóteses e cálculos teóricos de utilização de energia e proteína, mas não de dados concretos de desempenho animal (Santos et al., 1998b; Theurer et al., 1999).
A suplementação de vacas leiteiras com fontes ricas em proteína não degradável no rúmen (PNDR) tornouse prática comum e amplamente aceita, principalmente após a publicação do modelo de proteína absorvível (Absorbed Protein Model), pelo National Research Council (1985). Isto gerou e continua gerando intensa discussão sobre a importância da degradabilidade ruminal da proteína (Santos et al., 1998b).

Garthwaite et al. (1998) e Sloan et al. (1999) enfatizaram a importância do perfil de aminoácidos, especialmente lisina e metionina, na proteína metabolizável que chega ao intestino delgado de vacas leiteiras.

A última edição do National Research Council (2001), para gado leiteiro, incorporou o conceito de adequação das exigências protéicas para proteína metabolizável e preconizou a importância do ajuste dos teores de lisina e metionina nessa proteína. 
O objetivo deste trabalho foi avaliar fontes de amido (milho moído fino $\mathrm{x}$ milho processado como pipoca) e fontes protéicas (farelo de soja $\mathrm{x}$ uréia $\mathrm{x}$ farinha de peixe) com degradabilidades ruminais diferentes para alimentar vacas leiteiras.

\section{Material e Métodos}

Foram utilizadas 56 vacas Holandesas, confinadas em galpão de estabulação livre, que possuíam área de repouso individual. Os animais foram divididos em quatro lotes de 14 vacas cada; no total de 16 primíparas e 40 multíparas, com peso corporal médio de $565 \pm 70 \mathrm{~kg}$, $112 \pm 48$ dias em lactação e $33 \pm 6,6$ kg de leite ao início do experimento.

As vacas com mais de 60 dias de lactação receberam injeções de somatotropina bovina recombinante (Boostin) a cada 14 dias.

O experimento foi realizado para comparar três fontes protéicas (farelo de soja, FS; uréia, U; ou farinha de peixe, FP) e duas fontes de amido, uma de média degradabilidade ruminal (milho moído fino, $\mathrm{M}$ ) e outra de alta degradabilidade ruminal (resíduo industrial de pipoca doce, P). Foram avaliados quatro tratamentos: milho moído fino e farelo de soja (MFS); resíduo industrial de pipoca doce e farelo de soja (PFS); resíduo industrial de pipoca doce, farelo de soja e farinha de peixe (PFP); resíduo de pipoca doce, farelo de soja e uréia (PU).

Esses tratamentos foram formulados para resultar em rações isoprotéicas e isoenergéticas, utilizando-se o programa CPM-Dairy versão 1.0. Na formulação da ração que continha farinha de peixe, os teores de lisina e metionina foram próximos de 6,82 e 2,19\%, respectivamente, da proteína metabolizável, de acordo com as recomendações de Sloan et al. (1999). As rações experimentais foram formuladas para conter 14,6 a $19,9 \%$ de uma das fontes de amido e os respectivos suplementos protéicos (Tabela 1).

O delineamento experimental utilizado foi o de blocos ao acaso, com dez blocos compostos por vacas multíparas e quatro blocos por primíparas, o que totalizou 14 blocos. Os animais foram agrupados de acordo com a produção de leite, medida durante o período pré-experimental, o número de lactações (primípara ou multípara) e dias em lactação.

Nos dez dias que antecederam o período experimental, todas as vacas receberam a mesma ração, com $45 \%$ de silagem de milho, $10 \%$ de caroço de algodão, $9 \%$ de polpa cítrica peletizada, $8 \%$ de milho moído fino, $8 \%$ de resíduo industrial de pipoca doce (RPD), 17\% de farelo de soja, $3 \%$ de minerais, vitaminas e bicarbonato de sódio, formulada para conter $16,50 \%$ de proteína bruta, 1,7 Mcal de energia líquida para lactação, 32,50\% de fibra em detergente neutro e água. Neste período, as vacas tiveram suas produções de leite registradas diariamente por ocasião da ordenha, às 6 e 17h. No último dia desse período pré-experimental, foram realizadas amostragens do leite produzido por vaca (na proporção 1:1 entre as ordenhas da manhã e da tarde), para determinação de componentes do leite que, juntamente com os dados de produção, foram utilizados como covariáveis para análise dos dados do período experimental.

O período experimental teve duração de 60 dias. Os primeiros 14 dias foram utilizados para adaptação dos animais às rações experimentais. A coleta dos dados foi efetuada nos 46 dias restantes. Todas as vacas foram pesadas no início e final do experimento. Os escores de condição corporal de cada vaca também foram avaliados no primeiro e último dia, utilizando-se a escala de 1 a 5 (Wildman et al., 1982).

Os animais foram ordenhados às 6 e 17h, diariamente. As produções individuais foram registradas em cada ordenha, às segundas e sextas-feiras, por meio de medidores modelo MARK5 (De Laval). Foram tomadas amostras individuais de leite, coletadas na proporção de 1:1, entre as ordenhas da manhã e tarde das sextasfeiras, para análise dos teores de gordura, proteína, lactose e sólidos totais, pelo processo de infra-vermelho, na Clínica do Leite, do Dep. de Zootecnia, da Esalq.

Tabela 1. Proporção dos ingredientes nas rações experimentais em porcentagem de matéria seca.

\begin{tabular}{|c|c|c|c|c|}
\hline \multirow[t]{2}{*}{ Ingrediente } & \multicolumn{4}{|c|}{ Tratamentos $^{(1)}$} \\
\hline & MFS & PFS & PFP & $\mathrm{PU}$ \\
\hline Silagem de milho & 45,00 & 45,00 & 45,00 & 45,00 \\
\hline Caroço de algodão & 10,00 & 10,00 & 10,00 & 10,00 \\
\hline Polpa cítrica peletizada & 8,90 & 8,90 & 8,90 & 8,90 \\
\hline Resíduo de pipoca doce & - & 14,55 & 17,50 & 19,90 \\
\hline Milho moído fino & 16,00 & - & - & - \\
\hline Farelo de soja & 17,10 & 18,55 & 8,95 & 12,20 \\
\hline Farinha de peixe & - & - & 6,65 & - \\
\hline Uréia & - & - & - & 1,00 \\
\hline Minerais e vitaminas $^{(2)}$ & 3,00 & 3,00 & 3,00 & 3,00 \\
\hline
\end{tabular}

${ }^{(1)}$ MFS: milho moído fino com farelo de soja; PFS: pipoca com farelo de soja; PFP: pipoca com farelo de soja e farinha de peixe; PU: pipoca com farelo de soja e uréia. (2)Composição: Ca, 23,24\%; P, 5,50\%; K, 0,02\%; Mg, 3,50\%; Cl, 10,53\%; Na, 7,00\%; S, 2,20\%; 0,05\% de monensina sódica; e (por kg) $12 \mathrm{mg}$ de Co; $450 \mathrm{mg}$ de Cu; $40 \mathrm{mg}$ de I; $4.327 \mathrm{mg}$ de $\mathrm{Fe} ; 1.500 \mathrm{mg}$ de $\mathrm{Mn} ; 12 \mathrm{mg}$ de Se; $1.800 \mathrm{mg}$ de $\mathrm{Zn}$; 130.000 UI de vitamina A; 75.000 UI de vitamina D; 1.000 UI e vitamina E. 
O alimento foi fornecido para as vacas às 6 e 17h, utilizando-se vagão misturador de ração total. As sobras de alimento foram pesadas e descartadas, diariamente, antes do arraçoamento matutino, para fins de ajuste da quantidade a ser oferecida, de tal forma que houvesse aproximadamente $10 \%$ de sobras.

A silagem foi amostrada semanalmente, o concentrado foi amostrado a cada nova mistura, e as amostras foram armazenadas a $-18^{\circ} \mathrm{C}$. Subamostras da silagem foram secadas a $105^{\circ} \mathrm{C}$, para determinação do teor de matéria seca (MS), a fim se de proceder o ajuste semanal da formulação das rações.

Para análise em laboratório, as amostras de alimento foram compostas por período total, e subamostras do concentrado e da silagem foram secadas em estufas com ventilação forçada a $55^{\circ} \mathrm{C}$, por 72 horas, moídas em moinho tipo Wiley, provido de peneira com crivos com $1 \mathrm{~mm}$ de diâmetro, para determinação de matéria seca, cinzas e proteína bruta, de acordo com metodologias da Association of Official Analytical Chemists (1990); fibra em detergente neutro e fibra em detergente ácido foram determinadas de acordo com os métodos propostos por Van Soest et al. (1991) e adaptados para o aparelho ANKOM ${ }^{200}$.

No $60^{\circ}$ dia do experimento, foram coletadas amostras de sangue, através de punção na veia coccígea, às $0,2,4$ e 6 h após o fornecimento matinal do alimento, nas cinco vacas mais produtivas de cada tratamento, $o$ que totalizou 20 animais. Foram utilizados tubos de vidro a vácuo, com fluoreto de sódio como antiglicolítico e oxalato de potássio como anticoagulante. Depois da centrifugação das amostras de sangue a $3.000 \mathrm{~g}$ por 15 minutos, as amostras de plasma obtidas foram acondicionadas em tubos Eppendorf e congelados a $-10^{\circ} \mathrm{C}$.

O N uréico plasmático foi analisado de acordo com método colorimétrico (Chaney \& Marbach, 1962) e adaptado para a determinação da absorbância, utilizando-se placas de microtítulo com leitura em apa- relho do tipo ELISA Reader (filtro para obtenção de luz de $550 \mathrm{~nm}$ ).

Os dados de $\mathrm{N}$ uréico no plasma foram analisados como delineamento inteiramente casualizado com medidas repetidas no tempo (Littell et al., 1998), utilizando-se o PROC MIXED (SAS Institute, 1991). Os dados de produção e composição do leite foram analisados como delineamento de blocos ao acaso, com medidas repetidas no tempo, utilizando-se o PROC MIXED do SAS. Nessas análises com medidas repetidas no tempo, os efeitos de tratamento foram testados em relação às parcelas, e o tempo (horário ou dia da coleta) e as interações tempo e tratamento foram testadas com relação às subparcelas.

Para a avaliação da variação de peso corporal, foi adotado o delineamento em blocos ao acaso, utilizandose o PROC GLM (SAS Institute, 1991).

Todos os dados foram testados para se verificar a distribuição normal dos erros, utilizando-se o PROC Univariate (SAS Institute, 1991). Os dados que apresentaram erros fora do intervalo entre \pm 3 desvios foram arbitrariamente descartados da análise estatística.

Foi considerado o nível de significância de 5\% para a probabilidade do teste F. A hipótese de nulidade foi descartada na análise de variância, e na análise estatística foi utilizado o teste de Tukey, para comparação entre médias, tendo sido consideradas significativas, caso diferissem estatisticamente até 5\% de probabilidade. Todas as médias foram obtidas, usando-se o método dos quadrados mínimos (LS means).

\section{Resultados e Discussão}

Na Tabela 2, estão descritos os resultados da análise química das rações utilizadas neste trabalho, bem como de alguns ingredientes que as compunham.

Tabela 2. Composição química dos ingredientes utilizados, do concentrado e das rações completas em porcentagem de matéria $\operatorname{seca}^{(1)}$.

\begin{tabular}{|c|c|c|c|c|c|c|c|c|c|c|}
\hline Amostra & MS & $\mathrm{PB}$ & FB & EE & MM & ENN & NDT & FDA & FDN & Lig \\
\hline Silagem de milho & 27,59 & 8,42 & 26,21 & 2,34 & 4,68 & 58,35 & 64,14 & 30,15 & 48,84 & 3,93 \\
\hline Farelo de soja & 89,13 & 49,61 & 7,81 & 1,20 & 6,68 & 34,70 & 79,41 & - & - & - \\
\hline Farinha de peixe & 91,79 & 68,16 & 0,51 & 7,72 & 20,91 & 2,70 & 76,02 & - & - & - \\
\hline RPD & 94,40 & 5,35 & 1,57 & 1,67 & 0,25 & 91,16 & 82,51 & - & - & - \\
\hline Dieta MFS & 57,75 & 15,75 & - & - & 6,47 & - & - & - & 34,49 & - \\
\hline Dieta PFS & 45,88 & 16,00 & - & - & 5,84 & - & - & - & 30,50 & - \\
\hline Dieta PFP & 45,80 & 17,00 & - & - & 7,48 & - & - & - & 29,69 & - \\
\hline Dieta PU & 45,74 & 15,96 & - & - & 7,55 & - & - & - & 34,33 & - \\
\hline
\end{tabular}

(1)RPD: resíduo industrial de pipoca doce; MFS: milho moído fino com farelo de soja; PFS: pipoca com farelo de soja; PFP: pipoca com farelo de soja e farinha de peixe; PU: pipoca com farelo de soja e uréia. ${ }^{(2)}$ MS: matéria seca; PB: proteína bruta; FB: fibra bruta; EE: extrato etéreo; MM: matéria mineral; ENN: extrativo não nitrogenado; NDT: nutrientes digestíveis totais (calculado segundo National Research Council, 2001); FDA: fibra em detergente ácido; FDN: fibra em detergente neutro. 
O consumo de matéria seca (MS) apresentou valores numéricos mais elevados para o tratamento MFS, intermediários para PFS e PFP, e inferiores para PU (Tabela 3). Em razão de os animais terem recebido as rações em comedouro coletivo, não foi possível obter dados individuais para consumo de MS, o que impossibilitou a análise estatística, isto é, erro-padrão de média (EPM) e probabilidades, dos valores obtidos.

O menor valor numérico para consumo de MS da ração com pipoca (PFS), comparado com a dieta com milho moído fino (MFS), não está de acordo com a maioria dos trabalhos compilados por Theurer et al. (1999), que não mostraram diferença de consumo de MS entre rações com milho ou sorgo floculados, em comparação às de grãos processados menos intensamente. Entretanto, Oliveira et al. (1993), Santos et al. (1997a, 1997b) relataram menor consumo de MS para vacas que receberam sorgo floculado, comparado às que receberam sorgo laminado a seco.

Santos et al. (1997a) e Theurer et al. (1999) relataram que a floculação do sorgo ou milho em densidades inferiores a $360 \mathrm{~g} \mathrm{~L}^{-1}$ seria excessiva para vacas leiteiras, com efeito negativo no consumo de MS. Menores consumos de MS, em rações com fontes de amido de alta degradabilidade ruminal, podem estar relacionados à maior densidade energética do material floculado (estímulo de controles quimiostáticos do consumo) ou a efeitos negativos no ambiente ruminal.

Menores consumos de MS de rações com farinha de peixe, em comparação àquelas com farelo de soja, foram relatados na revisão feita por Santos et al. (1998b). Abu-Ghazaleh et al. (2001) também observaram tendência de redução no consumo de MS, quando a farinha de peixe foi incluída na ração, em teores similares ao utilizado neste trabalho.

Com base nos dados obtidos, pode-se inferir que a dose de farinha de peixe, incluída na ração de vacas de alta produção, com o objetivo de elevar os teores de lisina para valores próximos de $6,82 \%$ e de metionina para 2,19\% da proteína metabolizável, de acordo com as recomendações de Sloan et al. (1999), com utilização do software CPM-Dairy, pode ser excessiva e afetar negativamente o consumo de MS, além de ser economicamente inviável.

O menor valor numérico observado para consumo de MS, nas rações com 1\% de uréia, não está em conformidade com a maioria dos trabalhos revisados por Santos et al. (1998b). Em estudo conduzido com vacas leiteiras confinadas, Carmo et al. (2005) não observaram redução no consumo de MS de vacas, no terço final da lactação, que receberam rações com $2 \%$ de uréia, em comparação com vacas que não receberam suplementação de uréia na ração completa.

A suplementação com fonte de amido de alta degradabilidade ruminal (PFS), em comparação a de menor degradabilidade (MFS), não afetou $(p>0,05)$ as produções de leite e de leite corrigido para 3,5\% de gordura (LCG) (Tabela 3).

Theurer et al. (1999) relataram que a floculação do milho ou sorgo a $360 \mathrm{~g} \mathrm{~L}^{-1}$ aumentou, consideravelmente, a produção de leite e de LCG de vacas que receberam rações com feno de alfafa como volumoso exclusivo. Entretanto, Oliveira et al. (1993) e Santos et al. (1997a, 1997b) relataram que a fonte de amido de alta degradabilidade ruminal não aumentou a produção de leite, e que foram observados menores consumos de MS nessas rações. Neste caso, a vantagem para o material floculado ocorreu em termos de eficiência alimentar. O mesmo fato parece ter ocorrido neste trabalho, uma vez que as mesmas produções de leite e de LCG foram obtidas com consumo de MS numericamente inferior em 1,77 kg, para o tratamento com resíduo de pipoca (PFS) comparado ao do milho moído fino (MFS).

Tabela 3. Consumo de matéria seca, variação de peso corporal, produção e composição do leite nos diferentes tratamentos.

\begin{tabular}{|c|c|c|c|c|c|c|c|}
\hline \multirow[t]{2}{*}{ Variável $^{(1)}$} & \multicolumn{4}{|c|}{ Tratamentos $^{(2)}$} & \multirow[t]{2}{*}{$\mathrm{EPM}^{(3)}$} & \multicolumn{2}{|c|}{$\mathrm{P}^{(4)}$} \\
\hline & MFS & PFS & PFP & $\mathrm{PU}$ & & $\mathrm{T}$ & $\mathrm{T} * \mathrm{~S}$ \\
\hline Consumo MS (kg por dia) & 21,64 & 19,87 & 19,12 & 18,13 & ne & ne & ne \\
\hline Produção leite (kg por dia) & $31,80 \mathrm{ab}$ & $32,13 \mathrm{a}$ & $30,70 \mathrm{c}$ & $30,98 \mathrm{bc}$ & 0,59 & $<0,01$ & $\mathrm{~ns}$ \\
\hline LCG- $3,5 \%$ (kg por dia) & $30,89 a$ & $30,02 \mathrm{ab}$ & $26,64 \mathrm{c}$ & $29,50 \mathrm{~b}$ & 0,66 & $<0,01$ & ns \\
\hline Gordura $(\%)$ & $3,30 \mathrm{a}$ & $3,14 \mathrm{~b}$ & $2,73 c$ & $3,20 \mathrm{ab}$ & 0,06 & $<0,01$ & $<0,01$ \\
\hline Gordura (kg por dia) & $1,06 \mathrm{a}$ & $0,99 b$ & $0,83 \mathrm{c}$ & $0,99 b$ & 0,03 & $<0,01$ & $<0,05$ \\
\hline Proteína $(\%)$ & $3,12 b$ & $3,02 \mathrm{c}$ & $3,19 a$ & $3,06 \mathrm{bc}$ & 0,03 & $<0,01$ & ns \\
\hline Proteína (kg por dia) & 0,99 & 0,97 & 0,96 & 0,95 & 0,02 & ns & ns \\
\hline Variação de peso (kg) & 14,32 & 13,63 & 13,83 & 2,83 & 6,09 & $\mathrm{~ns}$ & ne \\
\hline
\end{tabular}

(1)LCG-3,5\%: produção de leite corrigida para 3,5\% de gordura. ${ }^{(2)}$ MFS: milho moído fino com farelo de soja; PFS: pipoca com farelo de soja; PFP: pipoca com farelo de soja e farinha de peixe; PU: pipoca com farelo de soja e uréia. (3)EPM: erro-padrão da média. ${ }^{(4)}$ Probabilidade do teste F; T: efeito de tratamento; T*S: efeito de interação tratamento e semana (tempo); ne: não estimado; ns: não-significativo. 
San Emeterio et al. (2000) obtiveram maior produção de leite em animais alimentados com milho moído fino (seco ou ensilado úmido), em comparação com a moagem grosseira, e o consumo de MS foi similar entre os animais que receberam rações com o grão de milho com diferentes tamanhos de partícula.

Pode-se afirmar, assim, que o aumento da degradabilidade ruminal do amido favorece o desempenho de vacas leiteiras de duas formas distintas: aumentando a produção de leite sem alteração no consumo de MS (Theurer et al., 1999) e, mantendo a produção de leite e reduzindo o consumo de MS (Oliveira et al., 1993; Santos et al., 1997a). Em ambos os casos a eficiência alimentar é melhorada. A ocorrência da primeira forma é mais provável, com rações nas quais os teores de amido ou de carboidratos não fibrosos (CNF), degradáveis no rúmen, estiverem adequados, assim como o teor de fibra efetiva da ração. A segunda forma é mais provável em casos de excesso de amido ou de CNF degradáveis no rúmen ou insuficiência de fibra efetiva na ração.

O fornecimento de milho processado na forma de pipoca, com o objetivo de aumentar a degradabilidade ruminal do amido, afetou a composição do leite (Tabela 3). O teor de gordura do leite foi reduzido $(p<0,01)$ no tratamento PFS, em relação ao tratamento MFS. Esse efeito tem sido observado na maioria dos trabalhos publicados sobre processamento de cereais para vacas leiteiras (Theurer et al., 1999; San Emeterio et al., 2000; Soriano et al., 2000).

A redução no teor de gordura do leite, com a suplementação de fontes de amido de maior degradabilidade ruminal, pode ser explicada de diversas formas. Apesar de o mecanismo exato pelo qual a síntese de gordura no leite é comprometida não estar ainda bem elucidado, algumas teorias têm sido propostas, como as que envolvem as mudanças que ocorrem na fermentação ou metabolismo ruminal e que resultam na diminuição de precursores de gordura para a glândula mamária (Van Soest, 1963). De acordo com o proposto por Gaynor et al. (1994) e Wonsil et al. (1994), a queda na síntese de gordura no leite ocorre em conseqüência da presença de componentes provenientes da ração ou da fermentação ruminal (como por exemplo os ácidos transoctadecenóicos), quando o pH ruminal é reduzido. Estes compostos inibem rotas metabólicas de biossíntese de ácidos graxos na glândula mamária .

Apesar da redução no teor de gordura do leite, na maioria dos trabalhos revisados por Theurer et al. (1999), a produção de gordura do leite foi aumentada por fontes de amido de alta degradabilidade ruminal, em função do aumento na produção de leite. Neste trabalho, a redução no teor de gordura do leite não foi compensada pelo aumento na produção de leite, quando a pipoca substituiu o milho moído fino, o que resultou em menor produção de gordura $(\mathrm{p}<0,01)$.

O teor de proteína do leite foi maior para o tratamento MFS, comparado ao PFS ( $\mathrm{p}<0,01$ ), enquanto a produção de proteína foi similar para os dois tratamentos. Esses dados não estão de acordo com Theurer et al. (1999), em que os autores relataram que o aumento da degradabilidade ruminal do amido, por meio da floculação do milho ou sorgo, resultou em maiores teor e produção de proteína do leite. A explicação mais aceita para o fato é o provável aumento no fluxo de proteína microbiana para o intestino e o conseqüente aumento no fluxo de proteína metabolizável (National Research Council, 2001). Além de maior disponibilidade de proteína metabolizável, esta poderá ser de melhor qualidade (perfil de AAE, especialmente lisina e metionina), em razão da maior participação da proteína microbiana (Sloan et al., 1999; National Research Council, 2001).

A ausência de efeito positivo do aumento da degradabilidade ruminal do amido sobre o teor de proteína do leite, neste trabalho, confirma os resultados publicados por Santos et al. (1997a, 1997b), em que o sorgo floculado reduziu o consumo de MS, não afetou a produção de leite e não aumentou o teor de proteína do leite, quando comparado ao sorgo laminado a seco.

Não houve efeito da fonte de amido no ganho de peso diário das vacas ( $>>0,05)$. De modo geral, as produções similares de leite, LCG e de proteína do leite, sem diferença de ganho de peso entre os tratamentos MFS e PFS, combinadas com menor consumo de MS na dieta PFS, sugerem que houve maior eficiência alimentar da fonte de amido de maior degradabilidade ruminal. Nos trabalhos de Oliveira et al. (1993) e Santos et al. (1997a,1997b), a floculação do sorgo não aumentou a produção de leite e de LCG, porém resultou em melhor conversão alimentar, em razão dos menores consumos de MS, nestas rações, em relação ao sorgo menos processado (laminado a seco).

A suplementação com diferentes fontes protéicas afetou a produção e a composição do leite neste trabalho (Tabela 3). A suplementação com farinha de peixe afetou $(\mathrm{p}<0,05)$ negativamente a produção de leite, o que discorda da maioria dos trabalhos revisados por Santos et al. (1998b). Santos (1998) e Santos et al. 
(1998a) também não observaram efeito positivo da farinha de peixe, em relação ao farelo de soja. Esses dois últimos tinham em comum com este trabalho a presença de fonte de amido de alta degradabilidade ruminal (sorgo floculado ou resíduo de pipoca) nas rações.

A alta degradabilidade ruminal do amido do milho, processado na forma de pipoca, pode ter propiciado alta síntese de proteína microbiana no rúmen, principalmente na ração com farelo de soja (PFS), mais rica em proteína degradável no rúmen (PDR) (National Research Council, 2001). Neste caso, pode diminuir a possibilidade de efeitos positivos da suplementação com fonte rica em PNDR de alta qualidade, como a farinha de peixe (National Research Council, 2001). Entretanto, neste trabalho, a inclusão de $6,65 \%$ de farinha de peixe na MS da ração parece ter sido excessiva. A redução expressiva no teor de gordura do leite, nesse tratamento, é forte indicativo de excesso de óleo de peixe na ração, conforme relatado na revisão de Santos et al. (1998b).

Na grande maioria dos trabalhos revisados por Santos et al. (1998b) em que ocorreram efeitos benéficos na produção de leite com o uso de farinha de peixe, as doses nas rações estiveram entre 2 e $4 \%$ da MS, o que reforça a possibilidade de ter havido inclusão excessiva desse ingrediente na ração neste trabalho. A inclusão de 5\% (Santos et al., 1998a) ou 6\% (Santos, 1998) de farinha de peixe, em rações com feno de alfafa como volumoso exclusivo para vacas de alta produção, não afetou a produção de leite nem o teor de gordura do leite. A inclusão de $6,65 \%$ de farinha de peixe foi adotada com o objetivo de atingir, com base na proteína metabolizável, concentrações de lisina e metionina próximas de 6,82 e 2,19\%, respectivamente, utilizando-se o programa CPM-Dairy.

A possibilidade de ter sido utilizada dose excessiva de farinha de peixe pode ser confirmada pela queda drástica do teor de gordura do leite das vacas que receberam esse suplemento (2,73\% para o PFP e 3,14\% para o PFS). Reduções no teor de gordura do leite com suplementação com farinha de peixe têm sido observadas em diversos trabalhos (Santos et al., 1998a; AbuGhazaleh et al., 2001) e atribuídas ao teor de óleo insaturado no produto. Em rações que contêm silagem de milho como volumoso exclusivo, esse problema é agravado, comparado com rações que contêm alfafa exclusivamente ou mesmo combinada com silagem de milho.
Além do efeito negativo na digestão de fibra, o que pode resultar em menor disponibilidade de acetato (Van Soest, 1963), o alto teor de óleo resultante da inclusão de farinha de peixe na ração pode resultar em maior passagem de ácidos graxos de cadeia trans para o intestino e, assim, para a glândula mamária, e reduzir a síntese de gordura do leite (Harfoot \& Hazelwood, 1988).

O maior $(\mathrm{p}<0,01)$ teor de proteína do leite, no tratamento com farinha de peixe (PFS), está de acordo com os resultados observados por Sloan et al. (1999) e Abu-Ghazaleh et al. (2001). Estes autores mostraram os benefícios do balanceamento de lisina e metionina na proteína metabolizável para vacas leiteiras, em termos de teor e produção de proteína do leite. De modo geral, quando a suplementação com farinha de peixe, na dose de 2 a $4 \%$ da MS, aumentou a produção de leite, em comparação com o farelo de soja, não foi observado aumento no teor de proteína do leite (Santos et al., 1998b). Em função da menor ( $\mathrm{p}<0,01)$ produção de leite no tratamento com farinha de peixe, em relação ao farelo de soja, a produção de proteína não foi aumentada $(p>0,05)$ pela fonte rica em PNDR de alta qualidade.

A suplementação com uréia (PU) afetou negativamente $(\mathrm{p}<0,01)$ a produção de leite. Não é possível afirmar que isto se deve ao menor fluxo de proteína metabolizável para o intestino, com essa ração, pois houve menor valor numérico para consumo de MS, comparado à ração com farelo de soja (PFS). Na revisão de Santos et al. (1998b), nas comparações em que não foram observadas diferenças nos consumos de MS nas rações com uréia, não houve efeito negativo desse suplemento na produção de leite, apesar de, numericamente, a uréia ter sido inferior às fontes de proteína verdadeira (32,7 e 33,3 kg de leite por vaca por dia, respectivamente). Entretanto, as produções de LCG, teores e produções de gordura e de proteína foram similares, quando houve substituição parcial do farelo de soja por uréia. O menor consumo de MS, observado nos animais que receberam a dieta PU, combinado com similar produção de LCG, gordura e proteína, sugere melhor conversão alimentar (consumo de MS/LCG) para o tratamento contendo uréia.

Não foi observado efeito $(p>0,05)$ de tratamento na variação de peso dos animais, entretanto, o tratamento PU resultou em menor ganho numérico.

Os dados relativos à concentração de $\mathrm{N}$ uréico no plasma dos animais, em razão do tratamento recebido, estão descritos na Tabela 4. O N uréico no plasma e no leite refletem o conteúdo de PB da dieta, bem como a 
qualidade dessa proteína, pois o excesso de amônia no rúmen vai para o fígado, através do sistema portahepático, para ser convertido em uréia. Como se trata de componente solúvel em água, parte dessa uréia passa a circular na corrente sangüínea, que irriga também a glândula mamária, podendo-se assim detectar aumentos de concentração por meio de análises laboratoriais do sangue e do leite.

À medida que fontes protéicas de menor degradabilidade ruminal foram suplementadas, houve redução $(p<0,05)$ na concentração de $\mathrm{N}$ uréico no plasma dos animais (Tabela 4). Entre as vacas tratadas com fontes de amido de alta degradabilidade ruminal, aquelas que receberam uréia na ração (PU) tiveram as maiores concentrações de $N$ uréico no plasma $(p<0,05)$, consideradas intermediárias para farelo de soja (PFS) e mais baixas para farinha de peixe (PFP). Esses dados estão de acordo com a literatura (National Research Council, 2001) e reforçam a idéia de que o teor de PDR na ração PU foi excessivo, o que resultou em maior perda de $\mathrm{N}$, quando comparado com os dados dos demais tratamentos.

Não houve efeito de degradabilidade ruminal de amido (MFS e PFS) sobre as concentrações de $\mathrm{N}$ uréico no plasma. Estes dados concordam com os de Santos (1998) e Theurer et al. (1999), nos quais foi relatado que a suplementação com fontes de amido de maior degradabilidade ruminal resultou menores concentrações plasmáticas de $\mathrm{N}$ uréico, em razão de aumentar a eficiência de uso do $\mathrm{N}$ no rúmen. Vale frisar que no âmbito geral os valores observados estão abaixo ou no limite considerado crítico para afetar parâmetros reprodutivos (National Research Council, 2001).

Tabela 4. Concentração, em mg dL $\mathrm{dL}^{-1}$, de nitrogênio uréico no plasma, conforme o horário de coleta, após o fornecimento matinal da alimentação.

\begin{tabular}{|c|c|c|c|c|c|c|}
\hline \multirow{2}{*}{$\begin{array}{c}\text { Tempo }^{(1)} \\
\text { (h) }\end{array}$} & \multicolumn{4}{|c|}{ Tratamentos $^{(2)}$} & \multirow[t]{2}{*}{$\mathrm{EPM}^{(3)}$} & \multirow{2}{*}{$\begin{array}{c}\text { Subparcela } \\
(p=0,52)\end{array}$} \\
\hline & MFS & PFS & PFP & PU & & \\
\hline 0 & 15,98 & 15,38 & 12,80 & 16,56 & 0,78 & 15,18 \\
\hline 2 & 17,82 & 15,20 & 13,80 & 17,38 & 0,72 & 16,05 \\
\hline 4 & 16,14 & 14,48 & 15,14 & 19,16 & 1,00 & 16,23 \\
\hline 6 & 14,64 & 15,26 & 11,35 & 17,62 & 0,92 & 14,72 \\
\hline EPM & 0,63 & 0,79 & 0,69 & 1,05 & & \\
\hline Parcela & $16,15 \mathrm{ab}$ & $15,08 \mathrm{bc}$ & $13,27 \mathrm{c}$ & $17,68 \mathrm{a}$ & & \\
\hline
\end{tabular}

(1)Horários de coleta de sangue, após o fornecimento matinal da alimentação; tempo zero, referente à coleta de sangue antes da alimentação. ${ }^{(2)}$ MFS: milho moído fino com farelo de soja; PFS: pipoca com farelo de soja; PFP: pipoca com farelo de soja e farinha de peixe; PU: pipoca com farelo de soja e uréia. ${ }^{(3)}$ Erro-padrão da média.
Não houve efeito dos tempos de coleta (subparcelas) nem da interação tratamento e tempo na concentração de $\mathrm{N}$ uréico no plasma.

\section{Conclusões}

1. A inclusão de amido de alta degradabilidade ruminal melhora a eficiência alimentar de vacas leiteiras de alta produção, alimentadas com silagem de milho como volumoso.

2. A utilização de $6,65 \%$ de farinha de peixe na ração com silagem de milho prejudica o desempenho de vacas leiteiras.

3. A substituição parcial do farelo de soja por $1 \%$ de uréia não prejudica a produção de sólidos do leite nem a conversão alimentar de vacas.

\section{Agradecimentos}

À Fapesp, pelo aporte financeiro; aos estagiários Flamarion Rigamonti Barbosa e João Paulo Vaienti Alves dos Santos, pelo auxílio na condução da fase de campo do experimento.

\section{Referências}

ABU-GHAZALEH, A.A.; SCHINGOETHE, D.J.; HIPPEN, A.R. Blood amino acids and milk composition from cows fed soybean meal, fish meal, or both. Journal of Dairy Science, v.84, p.11741181, 2001.

ASSOCIATION OF OFFICIAL ANALYTICAL CHEMISTS (Arlington, Estados Unidos). Official methods of analysis. $15^{\text {th }}$ ed. Arlington, 1990. v.1, 1117p.

CARMO, C.A.; SANTOS, F.A.P.; IMAIZUMI, H.; PIRES, A.V.; SCOTON, R.A. Substituição do farelo de soja por uréia ou amiréia para vacas em final de lactação. Acta Scientiarum, v.27, p.277-286, 2005.

CHANEY, A.L.; MARBACH, E.P. Modified reagents for determination of urea and ammonia. Clinical Chemistry, v.8, p.130132, 1962.

GARTHWAITE, B.D.; SCHWAB, C.G.; SLOAN, B.K. Protein and amino acid nutrition of the transition and early lactation dairy cow. In: CORNELL NUTRITION CONFERENCE, New York, 1998. Proceedings. Ithaca: Cornell University, 1998. p.38-50.

GAYNOR, P.J.; ERDMAN, R.A.; TETER, B.B.; SAMPUGNA, J.; CAPUCO, A.V.; WALDO, D.R.; HAMOSH, M. Milk fat yield and composition during abomasal infusion of cis or trans octadecenoates in Holstein cows. Journal of Dairy Science, v.77, p.157-165, 1994.

HARFOOT, C.G.; HAZELWOOD, G.P. Lipid metabolism in the rumen. In: HOBSON, P.N. (Ed.). The rumen microbial ecosystem. London: Elsevier Science, 1988. p.285-322. 
LITTELL, R.C.; HENRY, P.R.; AMMERMAN, C.B. Statistical analysis of repeated measures data using SAS procedures. Journal of Animal Science, v.76, p.1216-1231, 1998.

NATIONAL RESEARCH COUNCIL (Washington, Estados Unidos). Nutrient requirements of dairy cattle. $7^{\text {th }}$ ed. Washington: National Academy Press, 2001. 408p.

NATIONAL RESEARCH COUNCIL (Washington, Estados Unidos). Ruminant nitrogen usage. Washington: National Academy Press, 1985. 138p.

OLIVEIRA, J.S.; HUBER, J.T.; BEN-GHEDALIA, D.; SWINGLE, R.S.; THEURER, C.B.; PESSARAKLI, M. Influence of sorghum grain processing on performance of lactating dairy-cows. Journal of Dairy Science, v.76, p.575-581, 1993.

SAN EMETERIO, F.; REIS, R.B.; CAMPOS, W.E.; SATTER, L.D. Effect of coarse or fine grinding on utilization of dry or ensiled corn by lactating dairy cows. Journal of Dairy Science, v.83, p.28392848, 2000.

SANTOS, F.A.P. Efeito de fontes protéicas e processamento de grãos no desempenho de vacas de leite e digestibilidade dos nutrientes. 1998. 105p. Tese (Livre Docência) - Escola Superior de Agricultura Luiz de Queiroz, Piracicaba.

SANTOS, F.A.P.; HUBER, J.T.; THEURER, C.B.; SIMAS, J.M.; CHEN, K.H.; YU, P. Milk yield and composition of lactating cows fed steam-flaked sorghum and graded concentrations of ruminally degradable protein. Journal of Dairy Science, v.81, p.215-220, 1998a.

SANTOS, F.A.P.; HUBER, J.T.; THEURER, C.B.; SWINGLE, R.S.; SIMAS, J.M. Response of lactating dairy cows to various densities of sorghum grain. Journal of Animal Science, v.75, p.1681-1685, 1997b.

SANTOS, F.A.P.; HUBER, J.T.; THEURER, C.B.; SWINGLE, R.S.; WU, Z.; SIMAS, J.M.; CHEN, K.H.; CHAN, S.C.; SANTOS, J.; DePETERS, E.J. Comparison of barley and sorghum grain processed at different densities for lactating dairy cows. Journal of Dairy Science, v.80, p.2098-2103, 1997a.
SANTOS, F.A.P.; SANTOS, J.E.P.; THEURER, C.B.; HUBER, J.T. Effects of rumen-undegradable protein on dairy cow performance: a 12-year literature review. Journal of Dairy Science, v.81, p.31823213, 1998b.

SAS INSTITUTE (Cary, Estados Unidos). SAS/STAT user's guide: statistics, version 5. Cary, 1991. 1028p.

SLOAN, B.K.; GARTHWAITE, B.D.; SCHWAB, G.S. Fine-tuning sub-model may optimize production. Feedstuffs, v.71, p.11-15, 1999.

SORIANO, F.D.; POLAN, C.E.; MILLER, C.N. Milk production and composition, rumen fermentation parameters, and grazing behavior of dairy cows supplemented with different forms and amounts of corn grain. Journal of Dairy Science, v.83, p.15201529, 2000.

THEURER, C.B.; HUBER, J.T.; DELGADO-ELORDUY, A.; WANDERLEY, R. Invited review: summary of steam-flaking corn or sorghum grain for lactating dairy cows. Journal of Dairy Science, v.82, p.1950-1959, 1999.

VAN SOEST, P.J. Ruminant fat metabolism with particular reference to factors affecting low milk fat and feed efficiency: a review. Journal of Dairy Science, v.46, p.204-216, 1963.

VAN SOEST, P.J.; ROBERTSON, J.B.; LEWIS, B.A. Methods for dietary fiber, neutral detergent fiber, and nonstarch polysaccharides in relation to animal nutrition. Journal of Dairy Science, v.74, p.3583-3597, 1991.

WILDMAN, E.E.; JONES, G.M.; WAGNER, P.E.; BOMAN, R.L.; TROUTT, H.F.; LESCH, T.N. A dairy-cow body condition scoring system and its relationship to selected production characteristics. Journal of Dairy Science, v.65, p.495-501, 1982.

WONSIL, B.J.; HERBEIN, J.H.; WATKINS, B.A. Dietary and ruminally derived trans-18/1 fatty-acids alter bovine-milk lipids. Journal of Nutrition, v.124, p.556-565, 1994. 